\title{
PENGEMBANGAN SISTEM PENYEDIAAN AIR BERSIH DI KAWASAN PERUMAHAN GREEN KEMILING KECAMATAN KEMILING
}

\author{
Anwar \\ Dosen tetap Teknik Sipil Universitas Sang Bumi Ruwa Jurai \\ Email: minakshaka2013@gmail.com
}

\begin{abstract}
Abstrak
Melihat besarnya peran dan fungsi air bersih serta untuk mengantisipasi semakin tingginya kebutuhan air khususnya air bersih di Kawasan Perkotaan, maka perencanaan sistem air bersih harus mendapat perhatian yang serius. Pada saat ini dipastikan kinerja pelayanan air bersih di Kawasan Perkotaan masih sangat kurang terutama di kota metropolitan, kota besar, kota sedang dan kota kecil. Secara kuantitas air bersih yang diterima oleh warga, debit yang sampai ke pelanggan sangat kecil. Hal ini dimungkinkan adanya kebocoran air. Kualitas dari air bersih perlu dipertanyakan, karena dalam faktanya air bersih tersebut tidak layak konsumsi. Ditambah lagi dengan tidak mengalirnya air bersih selama 24 jam, air hanya mengalir sebentar dan itupun hanya dalam kuantitas yang kecil. Perumahan Green Kemiling merupakan kawasan perumahan baru yang berada di wilayah Kecamatan Kemiling Kota Bandar Lampung mempunyai luas wilayah sebesar 50,8 Ha. Selama ini untuk pemenuhan air bersih warga di sekitar perumahaan menggunakan air bersih sumur bor mengingat PDAM tidak dapat melayani air di daerah ini mengingat lokasi berada pada ketinggian yang tidak mampu dijangkau oleh sumber air yang ada. Akan tetapi berhubung potensi air di kawasan cukup besar, maka pihak perumahan merencanakan untuk mengembangkan sendiri. Kebutuhan air bersih dengan pelayanan $80 \%$ di zona pelayanan Perumahan Green Kemiling sampai dengan 2028 mencapai 72,926 liter/dtk. Pengembangan sistem penyediaan air bersih terdari dari pompa transmisi pompa dilakukan dengan pipa $200 \mathrm{~mm}$ dengan elevasi +28 menghasilkan kehilangan sebesar 5,646 $\mathrm{m}$ atau lebih rendah dari selisih elevasi pipa sumur dalam sebesar $7 \mathrm{~m}$. Jaringan transmisi air bersih dan pompa dari bak penampungan menuju reservoir distribusi menggunakan pipa HDPE $100 \mathrm{~mm}$ dengan elevasi dasar bak penampung $+25,75 \mathrm{~m}$ dengan kehilangan $\mathrm{hf}=$ $0,035 \mathrm{~m}$. Pembagian sistem air bersih dibagi menjadi 2 blok zona dengan kehilangan sebesar 0,280 m untuk blok I dan 3,665 m untuk blok II.
\end{abstract}

Kata kunci: air bersih, PDAM, pelayanan, sumur, penyediaan.

\section{DEVELOPMENT OF WATER SUPPLY SYSTEM IN THE HOUSING AREA OF GREEN KEMILING KEMILING SUB-DISTRICT}

\author{
Anwar \\ Lecturer of Civil Engineering University of Bumi Bumi Ruwa Jurai \\ Email: minakshaka2013@gmail.com
}

\begin{abstract}
See the magnitude of the role and function of clean air and to measure the speed of air. At this time ascertained its performance in urban areas is still very less in metropolitan city, big city, medium town and small town. In the quantity of clean water received by residents, the discharge that reaches the customer is very small. This is possible air leakage. The quality of clean water needs to be questioned, because in fact the clean air is not worth consumption. Coupled with no air flow for 24 hours, the air only flows briefly and even
\end{abstract}


then only in a small quantity. Housing Green Kemiling is a new residential area located in District Kemiling Bandar Lampung City has an area of $50.8 \mathrm{Ha}$. So far, for the fulfillment of clean water residents around the house using clean water wells remember PDAM can not serve the air in this area considering the location is at an altitude that can not be reached by the existing water source. Will want to connect to the air potential in the area is large enough, then the housing for its own development. Needs clean water with service 80\% in service zone Green Housing Housing up to 2028 reached 72,926 liters / sec. 200 $\mathrm{mm}$ with a +28 elevation resulting in a loss of $5.646 \mathrm{~m}$ or lower than the difference in pipe well elevation at a speed of $7 \mathrm{~m}$. The pipes and water from the pipe to the pipe with HDPE $100 \mathrm{~mm}$ with the base elevation of the reservoir $+25.75 \mathrm{~m}$ with loss $h f=0.035 \mathrm{~m}$. The distribution of clean water system is divided into 2 zone blocks with losses of $0.280 \mathrm{~m}$ for blocks I and 3,665 m for block II.

Keywords: clean water, PDAM, service, wells, supply.

\section{Pendahuluan}

Air merupakan salah satu fungsi utama dalam kehidupan makhluk hidup di muka bumi. Karena itu, keberadaan air perlu dilindungi agar dapat tetap bermanfaat bagi kehidupan manusia serta mahluk hidup lainnya. Perlindungan air yang dimaksud yaitu menjaga ketersediaan air baik dari segi kualitas maupun kuantitasnya. Pengertian tersebut menunjukkan bahwa air memiliki peran yang sangat strategis dan harus tetap tersedia dan lestari, sehingga mampu mendukung kehidupan dan pelaksanaan pembangunan di masa kini maupun di masa mendatang.

Keberadaan air bersih di daerah perkotaan menjadi lebih penting lagi mengingat aktivitas kehidupan masyarakat kota yang sangat dinamis. Dengan bertambahnya jumlah penduduk, maka kebutuhan akan air semakin meningkat tajam. Kawasan Perkotaan dengan tingkat pembangunan yang pesat dan pertumbuhan penduduk yang tinggi, air bersih merupakan barang yang langka dan mahal. Karena selain disebabkan oleh semakin tingginya kebutuhan akan air, juga terjadi penurunan kualitas dan kuantitas air. Penggunaan air di Kawasan Perkotaan antara lain adalah untuk air minum (permukiman), industri, usaha perkotaan (perdagangan/pertokoan) dan lainnya.

Melihat besarnya peran dan fungsi air bersih serta untuk mengantisipasi semakin tingginya kebutuhan air khususnya air bersih di Kawasan Perkotaan, maka perencanaan sistem air bersih harus mendapat perhatian yang serius. Karena perencanaan sistem air bersih merupakan salah satu faktor utama dalam pemenuhan kebutuhan air bersih di 
Kawasan Perkotaan. Pada saat ini dipastikan kinerja pelayanan air bersih di Kawasan Perkotaan masih sangat kurang terutama di kota metropolitan, kota besar, kota sedang dan kota kecil. Untuk memenuhi kebutuhan air bersih tersebut di daerah perkotaan bukan saja mengharapkan sumber air yang berasal dibangun beberapa pengolahan air bersih yang dikelola oleh Badan Usaha Milik Daerah yaitu Perusahaan Daerah Air Minum.

Penggunaan air bersih dari PDAM terkait dengan tiga hal, yaitu kualitas, kuantitas dan kontinuitas. Secara kuantitas air bersih yang diterima oleh warga, debit yang sampai ke pelanggan sangat kecil. Hal ini dimungkinkan adanya kebocoran air. Kualitas dari air bersih perlu dipertanyakan, karena dalam faktanya air bersih tersebut tidak layak konsumsi. Ditambah lagi dengan tidak mengalirnya air bersih selama 24 jam, air hanya mengalir sebentar dan itupun hanya dalam kuantitas yang kecil.

Permasalahan tersebut diperparah dengan adanya kehilangan air secara fisik dengan adanya kebocoran air pada jaringan distribusi yang tinggi akan mengakibatkan debit air yang sampai ke pelanggan menjadi kecil dan sedikit. Kehilangan air secara non fisik yaitu adanya kesalahan pada meter produksi dan meter pelanggan, pemakaian air tanpa menggunakan meter air, sambungan liar dan pencurian air, serta adanya kesalahan dalam membaca meter air. Kondisi di lapangan menunjukkan bahwa pelayanan yang selama ini dilakukan oleh PDAM belum optimal, bahkan masyarakat yang mempunyai penghasilan rendah belum dapat menikmati aliran air bersih dari PDAM karena pemasangan sambungan sangat mahal.

Perumahan Green Kemiling merupakan kawasan perumahan baru yang berada di wilayah Kecamatan Kemiling Kota Bandar Lampung mempunyai luas wilayah sebesar 50,8 Ha. Selama ini untuk pemenuhan air bersih warga di sekitar perumahaan menggunakan air bersih sumur bor mengingat PDAM tidak dapat melayani air di daerah ini mengingat lokasi berada pada ketinggian yang tidak mampu dijangkau oleh sumber air yang ada.

Dengan demikian, dengan potensi topografi yang ada memungkinkan munculnya perencanaan dan pengembangan sistem air bersih terpadu dan mandiri untuk suplai seluruh perumahan sehingga pemenuhan air bersih dapat dipenuhi. 


\section{Tinjauan Pustaka}

\section{Dasar Hukum Penyediaan Air Bersih}

Pelaksanaan kegiatan penyediaan air baku harus mengacu kepada dasar hukum yang berlaku. Undang-undang No. 7 Tahun 2004 Tentang Sumber Daya Air, didalamnya juga mengatur beberapa hal mengenai penyediaan air baku. Dalam Pasal 34 UU No. 7 Tahun 2004, dinyatakan bahwa pengembangan sumber daya air pada wilayah sungai ditujukan untuk peningkatan kemanfaatan fungsi sumber daya air guna memenuhi kebutuhan air baku untuk rumah tangga, pertanian, industri, pariwisata, pertahanan, pertambangan, ketenagaan, perhubungan, dan untuk berbagai keperluan lainnya.

\section{Air Tanah}

Air merupakan kebutuhan pokok setiap orang, karenanya seluruh masyarakat berkewajiban untuk menjaga dan melestarikan air. Sebagai upaya melestarikan air, pemerintah bersama masyarakat telah melakukan upaya konservasi air dan tanah. Konservasi ini diharapkan dapat menyelamatkan sumber air dan pelestarian lingkungan.

Sistem resapan air hujan atau aliran permukaan terdiri dari dua jenis, yaitu antara lain:
A. Sistem On-site, misalnya sumuran resapan diperkarangan rumah.

B. Sistem Off-site, (sistem terpusat) misal kolom retensi, tendon, atau waduk

Peresapan air hujan ini dapat dilakukan melalui:

A. Reboisasi

B. Terasering

C. Saluran Resapan

D. Bidang resapan, pada lahan parkir atau halaman/taman, dll.

\section{Kebutuhan Air Bersih}

Kebutuhan air bersih suatu daerah didasarkan pada jumlah penduduk daerah tersebut. Kimpraswil telah mengeluarkanPedoman/Petunjuk Teknik dan Manual Bagian 6: Air Minum Perkotaan, sebagai acuan untuk menghitung Kebutuhan air total.

\section{Standar Penyediaan Air}

Perhitungan proyeksi jumlah penduduk dilakukan untuk memprediksi kebutuhan air pada saat ini dan masa yang akan datang. Dalam hal ini jumlah penduduk dipandang sebagai kumpulan manusia dan perhitungannya disusun menurut berbagai statistik tertentu. Analisa yang umum digunakan adalah sebagai berikut (Supranto, 1984):

1. Analisa Linier

2. Analisa Logaritma 
3. Analisa Eksponensial

Standar penyediaan air domestik ditentukan oleh jumlah konsumen domestik yang dapat diketahui dari data penduduk yang ada. Standar penyediaan kebutuhan air domestik ini meliputi air minum, mandi, masak, dll.
Kecenderungan meningkatnya kebutuhan dasar air ditentukan kebiasaan pola hidup masyarakat setempat dan didukung oleh kondisi sosial ekonomi. Tabel di bawah ini menunjukkan kebutuhan air perseorangan tergantung dengan lokasinya.

Tabel 1 Konsumsi Air Bersih

\begin{tabular}{|l|l|c|c|c|}
\hline Kategori Kota & \multicolumn{1}{|c|}{ Jumlah Penduduk } & $\begin{array}{c}\text { Sambungan } \\
\text { Rumah } \\
\text { (L/orang/hari) }\end{array}$ & $\begin{array}{c}\text { Sambungan } \\
\text { Umum } \\
\text { (L/orang/hari) }\end{array}$ & $\begin{array}{c}\text { Kehilangan } \\
\text { Air }\end{array}$ \\
\hline Metropolitan & $>1.000 .000$ & 190 & 30 & $20 \%$ \\
\hline Kota Besar & $500.000-1.000 .000$ & 170 & 30 & $20 \%$ \\
\hline Kota Sedang & $100.000-500.000$ & 150 & 30 & $20 \%$ \\
\hline Kota Kecil & $20.000-100.000$ & 130 & 30 & $20 \%$ \\
\hline IKK & $<20.000$ & 100 & 30 & $20 \%$ \\
\hline
\end{tabular}

Sumber : Kebijaksanaan operasional program air bersih, Dirjen Cipta Karya

Standar penyediaan air non domestik ditentukan oleh banyaknya konsumen non domestik. Konsumen non domestik dapat dihitung mengikuti perkembangan standar penyediaan air domestik, seperti yang dapat dilihat pada tabel di bawah :

Tabel 2 Kebutuhan Konsumsi Air Konsumen Non Domestik

\begin{tabular}{|c|c|c|}
\hline \multicolumn{2}{|r|}{ Kategori } & Kebutuhan Air \\
\hline \multirow[t]{6}{*}{ Umum } & Masjid & $25-40$ L/orang/hari \\
\hline & Gereja & $5-15 \mathrm{~L} /$ orang/hari \\
\hline & Terminal & $15-20 \mathrm{~L} /$ orang/hari \\
\hline & Sekolah & $15-30$ L/orang/hari \\
\hline & Rumah Sakit & $220-300 \mathrm{~L} / \mathrm{t}$. tidur/hari \\
\hline & Kantor & $25-40$ L/orang/hari \\
\hline \multirow[t]{2}{*}{ Industri } & Peternakan & $10-35$ L/orang/hari \\
\hline & Industri Umum & $40-400$ L/orang/hari \\
\hline \multirow[t]{4}{*}{ Komersil } & Bioskop & $10-15 \mathrm{~L} / \mathrm{kursi} / \mathrm{hari}$ \\
\hline & Hotel & $80-120$ L/orang/hari \\
\hline & Rumah Makan & $65-90 \mathrm{~L} / \mathrm{meja} / \mathrm{hari}$ \\
\hline & Pasar / Toko & $5 \mathrm{~L} / \mathrm{m}^{2} /$ hari \\
\hline
\end{tabular}

Sumber : Ir. Sarwoko, Penyediaan Air Bersih 
Sistem Penyediaan Air Bersih

Merupakan usaha-usaha yang dilakukan untuk mengubah sifat-sifat suatu zat. Hal ini penting bagi air minum karena dengan adanya pengolahan ini maka akan didapatkan suatu air minum yang memenuhi standar air minum yang telah ditentukan.

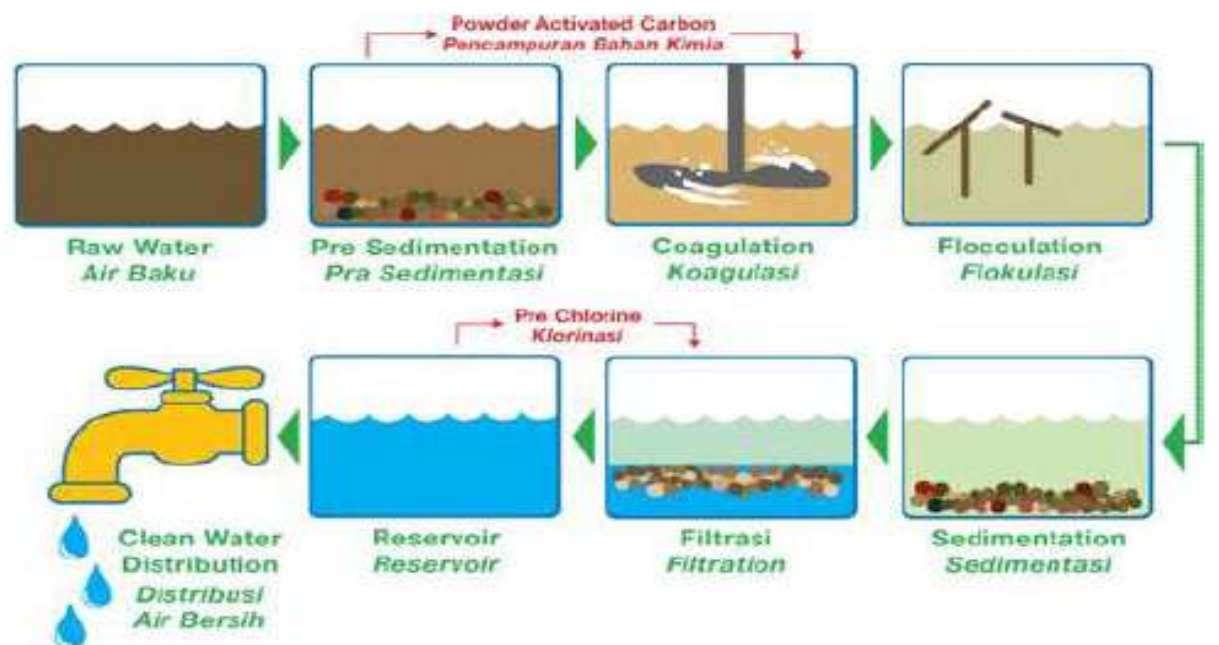

Gambar 1 Unit Pengelolaan Air (Sumber : www.cwsp.net/unit pengelolaan air)

\section{Jaringan Pipa}

Pipa merupakan komponen utama dalam jaringan perpipaan meliputi transmisi dan distribusi.

Tabel 3 Jenis Pipa serta Untung Rugi Penggunaannya

\begin{tabular}{|l|l|l|l|}
\hline No & Jenis Pipa & Keuntungan & Kerugian \\
\hline 1 & Bambu & Murah, mudah diperoleh & Cepat rusak, mudah bocor \\
\hline 2 & PVC & $\begin{array}{l}\text { Ringan, mudah diangkut dan dipasang, } \\
\text { tidak bereaksi dengan air }\end{array}$ & Tekanan rendah \\
\hline 3 & HDPE & $\begin{array}{l}\text { Ringan, mudah diangkut dan dipasang, } \\
\text { tidak bereaksi dengan air, panjang } \\
\text { mencapai 100 m tanpa sambungan kecil } \\
\text { untuk diameter kecil }\end{array}$ & Tekanan rendah \\
\hline 4 & Baja, Galvanized & Tekanan tinggi & Berat, transportasi dan instalasi \\
& Iron & & lebih mahal \\
\hline
\end{tabular}

Sumber : Triatmodjo, 2008

Untuk menghitung kehilangan tenaga dalam pipa distribusi digunakan persamaan Hazen - Williams sebagai berikut :

$\mathrm{V} \quad=0,3545 \mathrm{C}_{\mathrm{HW}} \mathrm{D}^{0,63} \mathrm{~S}^{0,54}$ 
Hf $=\left[\left(10,675 \times \mathrm{Q}^{1,852}\right) /\left(\mathrm{C}_{\mathrm{HW}} 1,852\right.\right.$ x D4,8704)] x L

$\mathrm{D}=\left[\left(10,675 \times \mathrm{Q}^{1,852}\right) /\left(\mathrm{C}_{\mathrm{HW}} 1,852\right.\right.$ $\mathrm{x}$ D4,8704) ] ${ }^{0,205}$

dengan :

$\mathrm{V}=$ Kecepatan rata - rata dalam pipa $(\mathrm{m} / \mathrm{s})$

$\mathrm{C}_{\mathrm{HW}}=$ Koefisien kekasaran Hazen -

Williams (tergantung jenis pipa)

$\mathrm{S}=$ Gradien Hidrolik $\left(\mathrm{S}=\mathrm{H}_{\mathrm{f}} / \mathrm{L}\right)$

Hf = Kehilangan tenaga $(\mathrm{m})$

$\mathrm{Q}=\operatorname{Debit}\left(\mathrm{m}^{3} / \mathrm{s}\right)$

$\mathrm{L} \quad=$ Panjang pipa $(\mathrm{m})$

Dalam perencanaan dimensi pipa harus memenuhi ketentuan teknis sebagai berikut:

1. Pipa harus direncanakan untuk mengalirkan debit maksimum harian;

2. Kehilangan tekanan dalam pipa tidak lebih $30 \%$ dari total tekanan statis (head statis) pada sistem perpipaan dengan pemompaan. Untuk sistem gravitasi, kehilangan tekanan maksimum 5 m/1000 m.

Hidrolika Pada Jaringan Pipa Air Bersih

Air dalam pipa selalu mengalir dari tempat yang memiliki energi besar menuju tempat yang memiliki tinggi energi lebih kecil. Aliran tersebut memiliki tiga macam energi yang bekerja di dalamnya, yaitu (Priyantoro, 1991:5), yaitu :

1. Energi kinetik, yaitu energi yang ada pada partikel massa air sehubungan dengan kecepatannya.

2. Energi tekanan, yaitu energi yang ada pada partikel massa air sehubungan dengan tekanannya.

3. Energi ketinggian, yaitu energi yang ada pada partikel massa air sehubungan dengan ketinggiannya terhadap garis refrensi (datum line).

\section{Desain Reservoir}

Secara umum cara analitis dipilih lebih praktis karena perhitungan kapasitas berdasarkan data suplai kebutuhan air bersih. Besarnya pemakaian air yang diperoleh berkaitan dengan kapasitas pompa yang akan digunakan dalam kajian ini, dengan rumus sebagai berikut: $\mathrm{P} \quad=100 \% /$ Jumlah jam pemakaian pompa

Prosentase selisih debit prosen suplai - prosen pemakaian Prosentase volume reservoir prosen selisih debit kumulatif Prosentase kapasitas reservoir : $\%$ vol terbesar - \% vol terkecil

Volume reservoir

Prosen kapasitas reservoir x Qhm 


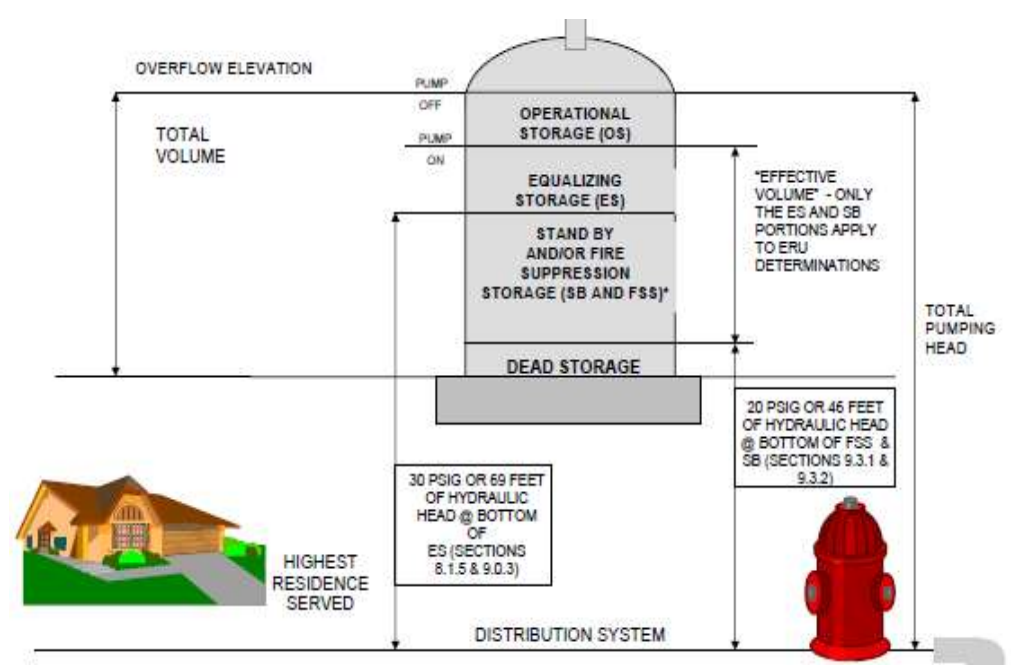

Gambar 2 Konsep Desain Pengelolaan Air Bersih (Sumber: Water System Manual)

\section{Metode Penelitian}

\section{Lokasi Penelitian}

Studi kasus ini dilakukan di kawasan permukiman di Kecamatan Kemiling Kota Bandar Lampung.

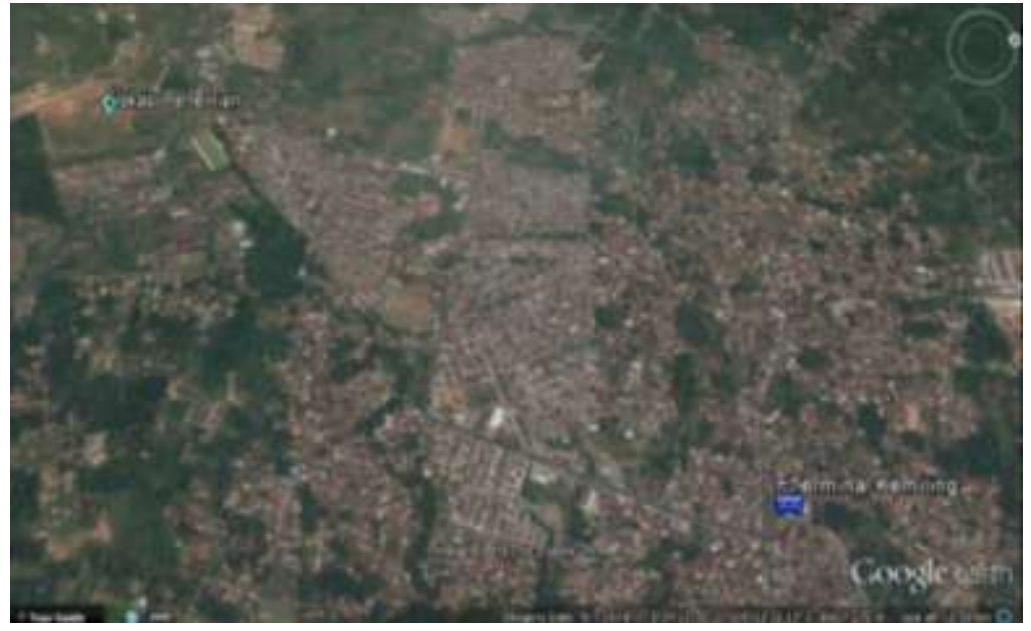

Gambar 3 Lokasi Penelitian (Sumber: Google Earth)

\section{Metode Penelitian}

Pada bagian ini akan dibahas mengenai metode penelitian untuk mengkaji sistem penyediaan air bersih pada daerah kajian. Untuk mengkaji sistem tersebut diperlukan suatu tahapan penelitian yaitu dengan cara mengumpulkan data teknis dan pendukungnya.

\section{Sumber Data}

Sumber data yang diperoleh penulis dalam penelitian ini berasal dari : 
Data Primer, yaitu data yang diperoleh dengan peninjauan secara langsung ke lapangan yang menjadi objek penelitian. Data primer yang diperlukan untuk penelitian ini antara lain meliputi data pengukuran elevasi dan site plan perumahan Green Kemiling.

Data Sekunder, yaitu data yang diperoleh dari literatur-literatur yang berhubungan dengan penelitian penulis, literatur ini dapat berupa data kependudukan, buku jurnal, browsing internet, jurnal yang berhubungan dengan penelitian penulis.

\section{Teknik Pengumpulan Data}

Agar didapat data yang dapat diuji kebenarannya, relevan, dan lengkap, maka penulis menggunakan metode atau teknik dalam pengumpulan data tersebut. Metode pengumpulan data tersebut yang digunakan penulis dalam penelitian ini adalah:

\section{Studi Lapangan: Studi lapangan} dilakukan untuk memperoleh data primer dengan melakukan pengukuran standar rencana perumahan untuk memastikan elevasi tertinggi dan elevasi terendah rencana perumahan.

Studi Kepustakaan: Studi kepustakaan dilakukan untuk memperoleh data sekunder guna mendukung data primer yang diperoleh. Pengumpulan data sekunder ini dilakukan dengan cara membaca dan mempelajari buku-buku referensi yang berhubungan dengan masalah yang diteliti.

\section{Kriteria Perencanaan Pengelolaan Air}

\section{Bersih}

Dasar yang akan digunakan dalam pengelolaan air bersih kawasan perumahan yaitu :

a. Perkiraan pengembangan pada waktu sekarang dan proyeksi di masa yang akan datang.

b. Kondisi fisik perumahan, jumlah perumahan, data topografi.

c. Pembagian wilayah distribusi air bersih.

d. Kebutuaan air berdasarkan ketersediaan dan fasilitas yang akan dibutuhkan dalam proses distribusi.

\section{Tahapan dan Prosedur Penelitian}

Penelitian akan bisa dilaksanakan dengan baik jika telah dilakukan rencana tahapan pelaksanaan dan prosedur analisis yang benar. Dalam penelitian ini dilakukan tahapan pelaksanaan dan prosedur sebagai berikut:

1. Identifikasi masalah

2. Studi pustaka dan pengumpulan data

3. Proyeksi kebutuhan air bersih perumahan

4. Desain tampungan air (reservoir) berdasarkan perumusan yang telah dijelaskan pada bab sebelumnya 
5. Desain sistem pemipaan

6. Skenario operasi air bersih.

\section{Hasil Dan Pembahasan}

\section{Kondisi Umum Lokasi Kegiatan}

Lokasi penelitian meliputi rencana pembangunan perumahan Green
Kecamatan Kemiling Kota Bandar Lampung. Kondisi lahan rencana lokasi perumahan merupakan lahan berbukit dengan luas lahan \pm 10 hektar. Gambar di bawah ini menunjukkan peta lokasi dan topografi hasil pengukuran topografi yang diperoleh dari data sekunder Kemiling di Jalan Teuku Cik Ditiro

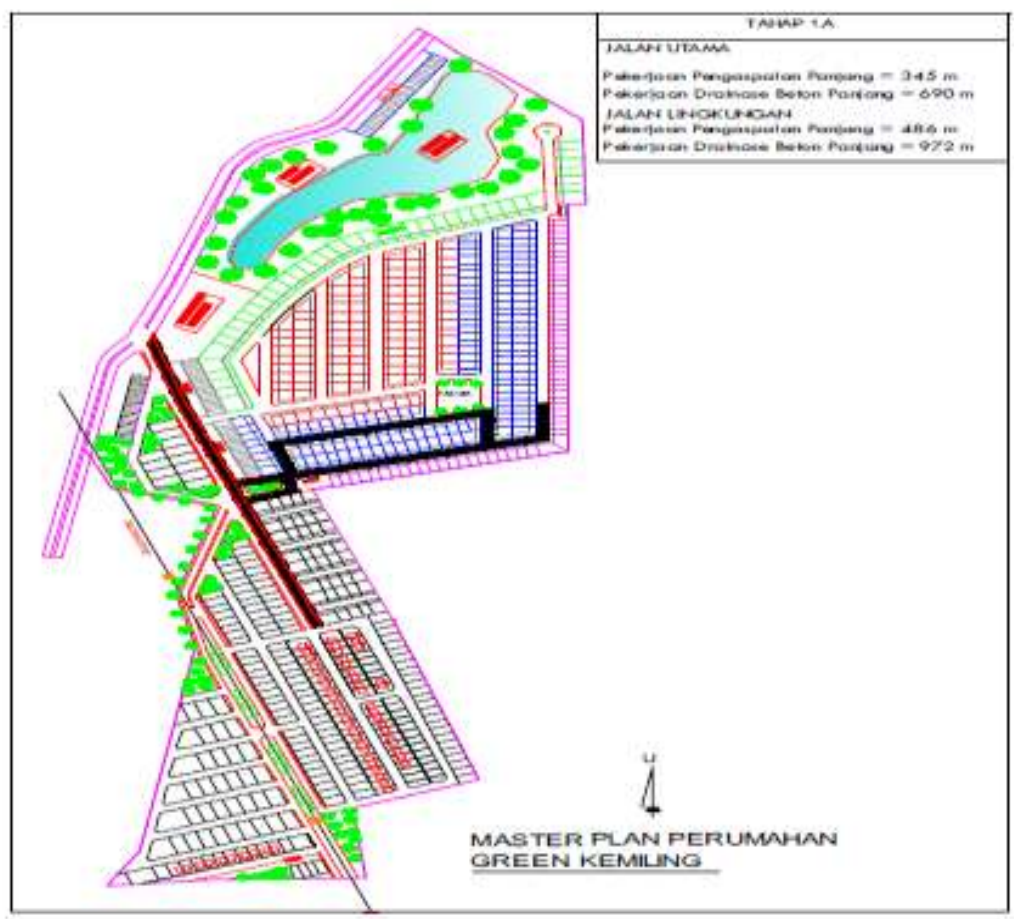

Gambar 3 Masterplan Perumahan Green Kemiling

\section{Kondisi Eksisting Sistem Penyediaan}

\section{Air}

Untuk memenuhi kebutuhan air di sekitar kawasan rencana perumahan ini sebagian besar masyarakat menggunakan jasa perusahaan air minum PDAM Way Rilau. Masalah yang dihadapi saat ini adalah rendahnya tingkat pelayanan kepada masyarakat, suplai air tidak berjalan lancar bahkan sering mati air. Permasalahan yang terjadi kemungkinan disebabkan rendahnya tekanan air baik akibat elevasi di lokasi kegiatan merupakan elevasi yang tinggi, kebocoran maupun pemasangan illegal yang mengakibatkan sejumlah daerah pelayanan tidak teraliri air secara optimal seperti yang terjadi di perumahan di 
sekitar kawasan rencana perumahan Oleh karena minimnya pelayanan yang diberikan oleh PDAM, banyak masyarakat yang semula menjadi pelanggan terpaksa harus mencari sumber air lain seperti membuat sumur dangkal ataupun sumur bor sendiri.

Berdasarkan data eksisting, bahwa pelayanan IPA Paal 2 B (Kecamatan Kemiling) hanya sekitar 23 SR yang terlayani dari 548 unit rumah di lokasi yaitu dengan total pemakaian air yaitu $520 \mathrm{~m}^{3} /$ bulan atau sebesar 0,201 liter/detik.

\section{Analisa Pertumbuhan Penduduk}

Berdasarkan hasil analisa diketahui trend regresi terbaik dengan $r^{2}$ terbesar dan $\mathrm{Se}$ terkecil untuk kawasan perumahan Green Kemiling dan cakupan kawasan perumahan yang ada dihitung dengan Persamaan sebagai berikut:

$\mathrm{Y}=348,48+165,3 \mathrm{x}$

Maka jumlah penduduk untuk proyeksi penduduk perumahan dalam kurun waktu 2014 - 2027 adalah sebagai berikut (berdasarkan total unit perumahan yang akan dipasarkan)

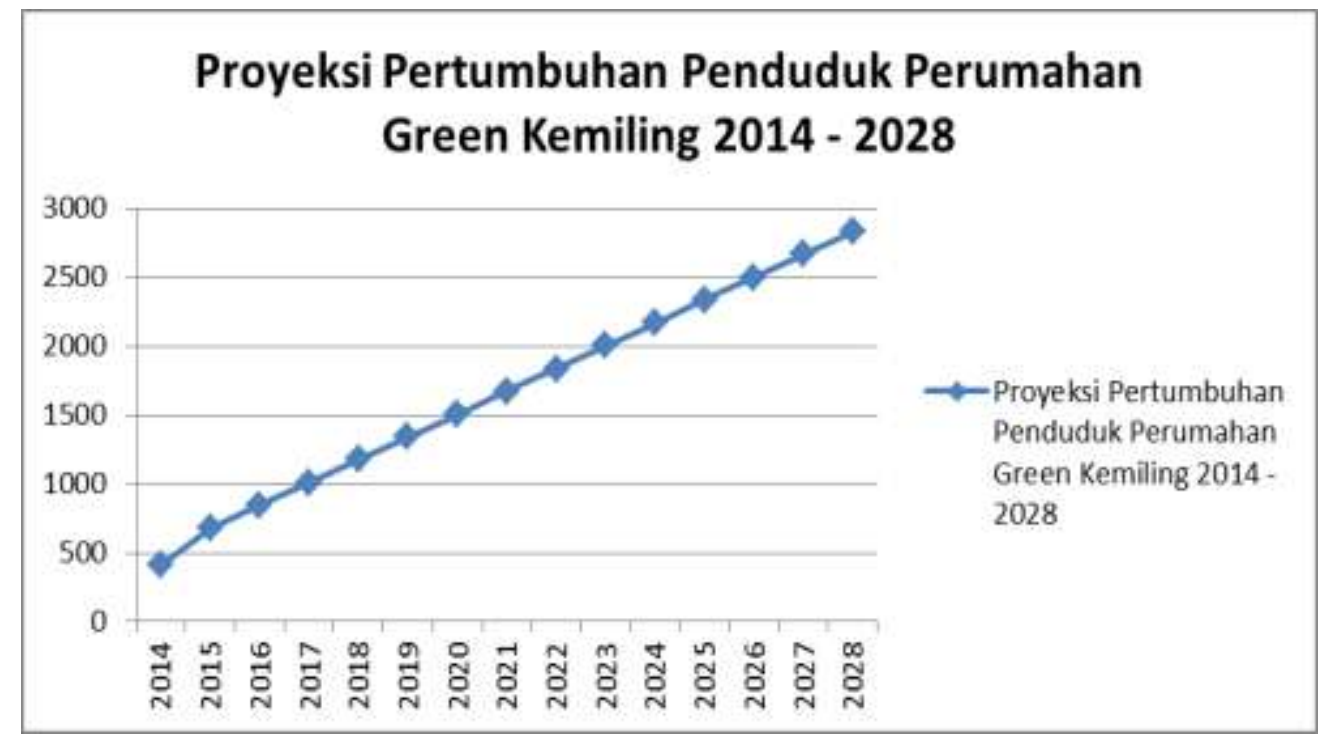

Gambar 4 Proyeksi Pertumbuhan Penduduk Perumahan Green Kemiling 2014 - 2028

\section{Analisis Kebutuhan Air}

Tabel di bawah ini menunjukkan jumlah kebutuhan air Domestik, Non Domestik, kehilangan air dam kebutuhan air total dengan pelayanan $80 \%$ untuk zona pelayanan IPA Sea. 
Tabel 4 Kebutuhan Air di Perumahan Green Kemiling

\begin{tabular}{|c|c|c|c|c|c|}
\hline \multirow{3}{*}{ Tahun } & Jumlah Jiwa & Keb. Air Domestik & Keb. Air Non Domestik & Kehilangan Air & Total Kebutuhan \\
\hline & (Orang) & (Qd) (liter/dtk) & (Qn) (liter/dtk) & (Qa) (Itr/dtk) & Air (Qtot) (It/dtk) \\
\hline & & $\mathrm{Qd}=\mathrm{Pn} \times 160 \mathrm{lt} / \mathrm{or} / \mathrm{hr}$ & $Q n=Q d \times 15 \%(I t / d t k)$ & $(Q a=(Q d+Q n) * 40 \%$ & $Q$ tot $=Q d+Q n+Q a$ \\
\hline 2014 & 412 & $6,592.00$ & 988.80 & $3,032.32$ & $10,613.12$ \\
\hline 2015 & 680 & $10,872.00$ & $1,630.80$ & $5,001.12$ & $17,503.92$ \\
\hline 2016 & 845 & $13,520.00$ & $2,028.00$ & $6,219.20$ & $21,767.20$ \\
\hline 2017 & 1011 & $16,168.00$ & $2,425.20$ & $7,437.28$ & $26,030.48$ \\
\hline 2018 & 1176 & $18,816.00$ & $2,822.40$ & $8,655.36$ & $30,293.76$ \\
\hline 2019 & 1342 & $21,464.00$ & $3,219.60$ & $9,873.44$ & $34,557.04$ \\
\hline 2020 & 1507 & $24,112.00$ & $3,616.80$ & $11,091.52$ & $38,820.32$ \\
\hline 2021 & 1673 & $26,760.00$ & $4,014.00$ & $12,309.60$ & $43,083.60$ \\
\hline 2022 & 1838 & $29,408.00$ & $4,411.20$ & $13,527.68$ & $47,346.88$ \\
\hline 2023 & 2004 & $32,056.00$ & $4,808.40$ & $14,745.76$ & $51,610.16$ \\
\hline 2024 & 2169 & $34,704.00$ & $5,205.60$ & $15,963.84$ & $55,873.44$ \\
\hline 2025 & 2335 & $37,352.00$ & $5,602.80$ & $17,181.92$ & $60,136.72$ \\
\hline 2026 & 2500 & $40,000.00$ & $6,000.00$ & $18,400.00$ & $64,400.00$ \\
\hline 2027 & 2666 & $42,648.00$ & $6,397.20$ & $19,618.08$ & $68,663.28$ \\
\hline 2028 & 2831 & $45,296.00$ & $6,794.40$ & $20,836.16$ & $72,926.56$ \\
\hline
\end{tabular}

\section{Analisis Ketersediaan Air}

Berdasarkan hasil perhitungan diperoleh kebutuhan air bersih rencana pada tahun 2028 adalah sebesar 72,926 liter/detik. Dengan demikian dapat dilihat bahwa ketersediaan air saat ini sudah tidak dapat mencukupi kebutuhan air bersih pada tahun 2027. Oleh sebab itu, pengembangan yang direncanakan untuk mengatasi kekurangan air pada tahun 2028 adalah dengan cara menambah kapasitas dengan memanfaatkan sumber air dari jaringan pipa PDAM yang sudah ada disekitar daerah perumahan, direncanakan air akan diambil dari pipa Ø200 mm. Berdasarkan informasi yang diberikan dari pihak PDAM Way Rilau debit air untuk zona layanan di Kecamatan Kemiling tersebut sekitar 90 $\mathrm{m}^{3} /$ jam atau sama dengan 25 liter/detik.

\section{Sistem Pengembangan Penyediaan Air}

\section{Bersih}

Pengembangan sistem penyediaan air bersih untuk Perumahan Green Kemiling membutuhkan sistem pemompaan lengkap yang berguna untuk meningkatkan tekanan agar air dapat berjalan dengan lancar ke daerah yang elevasinya lebih tinggi. Awalnya suplai air di kawasan perumahan disuplai dari PDAM Way Rilau. Akan tetapi berhubung potensi air di kawasan cukup besar, maka pihak perumahan merencanakan untuk mengembangkan sendiri jaringan suplai air bersih. Mula mula, air yang disuplai dengan pompa akan ditampung terlebih dahulu pada bak penampung kemudian dipompa melalui pipa transmisi menuju reservoar distribusi pada daerah yang letak 
elevasinya lebih tinggi dari daerah layanan, kemudian air dari reservoar distribusi akan disalurkan ke daerah layanan melalui pipa distribusi secara gravitasi mengikuti pola alur persebaran rumah penduduk, dan pola alur aliran didesain mengikuti elevasi yang ada. Pengembangan yang direncanakan untuk mengatasi kekurangan air yaitu dengan cara menambah kapasitas ketersediaan air menjadi 72,926 liter/detik. Adapun rencana pengembangan sistem penyediaan air bersih perumahan Green Kemiling yaitu:

\section{Dengan Jaringan Transmisi Pompa} Sumur Dalam dengan Pipa Ø 200mm ke Bak Penampung

Kedalaman sumur yang direncanakan adalah $100 \mathrm{~m}$. Pipa yang direncanakan adalah pipa jenis HDPE berdiameter 100 $\mathrm{mm}$ dengan panjang pipa adalah $251 \mathrm{~m}$. Pipa tersebut dilengkapi dengan gate valve dan meter air agar dapat mengatur dan mengalirkan debit air sebesar 72,926 liter/detik menuju bangunan bak penampung. Perhitungan pipa transmisi dilakukan secara manual dengan menggunakan rumus Hazen- Williams adalah sebagai berikut:

Elevasi Pipa Sumur Dalam $=+28$
Elevasi Bak Penampung $\quad=+21$
$\mathrm{~L}=251 \mathrm{~m}$

$\mathrm{Q}=72,926$ liter/dtk

$\mathrm{CHw}=140$

$\mathrm{D}=200 \mathrm{~mm}=0,2 \mathrm{~m}$

Kehilangan dalam pengaliran:

$$
\begin{aligned}
H f & =\frac{10,675 x Q^{1,852}}{C H W^{1,852} x D^{4,8704}} x L \\
H f & =\frac{10,675 \times 0,072926^{1,852}}{140^{1,852} \times 0,2^{4,8704}} x L \\
& =5,646 \mathrm{~m}
\end{aligned}
$$

Kontrol:

$\mathrm{Hf}<\Delta \mathrm{H}$ (Elevasi pipa sumur dalam)

$5,646 \mathrm{~m}<(28 \mathrm{~m}-21)$

$5,646 \mathrm{~m}<7 \mathrm{~m}$ oke

Menghitung kecepatan aliran dalam pipa dapat dihitung dengan persamaan:

$$
\begin{aligned}
\mathrm{v} & =0,3545 \mathrm{C}_{\mathrm{HW}} \mathrm{D}^{0,63} \mathrm{~S}^{0,54} \\
\mathrm{~S} & =\mathrm{Hf} / \mathrm{L} \\
& =5,646 / 251=0,0224 \\
\mathrm{v} & =0,3545 \times 140 \times 0,2^{0,63} 0,0224^{0,54} \\
\mathrm{v} & =0,803 \mathrm{~m} / \mathrm{s}
\end{aligned}
$$

Jaringan Transmisi Air Bersih dan Pompa dari Bak Penampungan Menuju Reservoir Distribusi

Pipa yang direncanakan adalah jenis pipa HDPE berdiameter $100 \mathrm{~mm}$ dengan panjang pipa adalah 191m. Pipa transmisi mulai dari bak penampung tersambung dengan pompa, pipa ini mengalirkan debit air sebesar 72,926 liter/detik ke reservoar distribusi. Dimana elevasi untuk rumah pompa $+28 \mathrm{~m}$, reservoar distribusi $+37 \mathrm{~m}$ dan elevasi dasar bak 
penampung $+25,75 \mathrm{~m}$. Perhitungan pipa dan pompa dari bak penampung ke reservoar distribusi dilakukan secara manual dengan menggunakan rumus Hazen-Williams adalah sebagai berikut:

$$
\begin{array}{ll}
\mathrm{H} & =2,75 \mathrm{~m} \\
\mathrm{H} 1 & =0,5 \mathrm{~m}
\end{array}
$$

$$
\begin{array}{ll}
\mathrm{H} 2 & =2,75-0,5=2,25 \mathrm{~m} \\
\mathrm{~L} & =5 \mathrm{~m} \\
\mathrm{Q} & =72,926 \text { liter } / \mathrm{dtk} \\
\mathrm{D} & =100 \mathrm{~m}=0,1 \mathrm{~m} \\
\mathrm{CHW} & =140
\end{array}
$$

Elevasi rumah pompa $\quad=+28$

Elevasi dasar bak penampung $=+25,75 \mathrm{~m}$

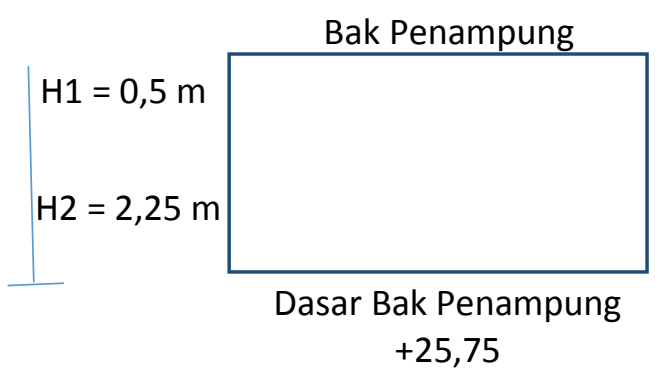

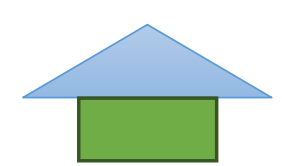

Rumah Pompa $+28 \mathrm{~m}$

$\mathrm{L}=5 \mathrm{~m}$

Gambar 5 Sketsa Bak Penampung Ke Pompa

Maka nilai Hf :

$$
\begin{aligned}
H f & =\frac{10,675 \times Q^{1,852}}{C H W^{1,852} \times D^{4,8704}} \times L \\
H f & =\frac{10,675 \times 0,072926^{1,852}}{140 \times D 0,1^{4,8704}} x L \\
& =0,035 \mathrm{~m}
\end{aligned}
$$

\section{Pipa Distribusi Dari Reservoar}

\section{Distribusi ke Pelanggan}

Pipa distribusi yang digunakan untuk mendistribusikan air dari reservoar distribusi menuju pelanggan adalah jenis

\begin{tabular}{|c|c|c|c|c|c|}
\hline \multirow{2}{*}{ Lokasi } & \multirow[t]{2}{*}{ Blok } & $\begin{array}{c}\text { Jumlah } \\
\text { Penduduk }\end{array}$ & $\begin{array}{l}\text { Persentasi } \\
\text { Penduduk }\end{array}$ & Debit Masuk & Debit Keluar \\
\hline & & (Jiwa) & $(\%)$ & (Lt/dtk) & (Lt/dtk) \\
\hline \multirow{2}{*}{$\begin{array}{c}\text { Green } \\
\text { Kemiling }\end{array}$} & Blok I & 1675 & 59.17 & \multirow{2}{*}{72.926} & 43.151 \\
\hline & Blok II & 1156 & 40.83 & & 29.775 \\
\hline Total & & 2831 & 100.00 & & 72.926 \\
\hline
\end{tabular}
pipa PVC. Analisa jaringan distribusi hanya sampai pada jalur pipa distribusi utama saja. Untuk jaringan pipa distribusi ke tiap rumah-rumah tidak diperhitungkan. Direncanakan analisa jaringan distribusi hanya terbagi dua jaringan utama saja atau dua zona pembagian.

Tabel 5 Hasil Perhitungan Debit Tiap Zona Pelayanan 
Pipa Distribusi yang Direncanakan Untuk Blok I

Debit (q) $=72,926$ liter $/ \mathrm{dtk}$

Panjang pipa $=46 \mathrm{~m}$

$\mathrm{D}$

$=100 \mathrm{~mm}$

$\mathrm{C}_{\mathrm{HW}}$ $=150$

- Kehilangan dalam pengaliran

$H f=\frac{10,675 x Q^{1,852}}{C H W^{1,852} x D^{4,8704}} x L$

$H f=\frac{10,675 \times 0,07926^{1,852}}{150^{1,852} \times 0,1^{4,8704}} x L \quad=0,280 \mathrm{~m}$

- Kontrol

$\mathrm{Hf}<\Delta \mathrm{H}$ (Elevasi pipa reservoir - Elevasi di Zona 1)

$0,280 \mathrm{~m}<2 \mathrm{~m}$ ok

- Menghitung Kecepatan Aliran

$$
\begin{aligned}
& \mathrm{v} \quad=0,3545 \mathrm{C}_{\mathrm{HW}} \mathrm{D}^{0,63} \mathrm{~S}^{0,54} \\
& \mathrm{~S} \quad=\mathrm{Hf} / \mathrm{L}=0,280 / 46=0,00609 \\
& \mathrm{v} \quad=0,3545 \times 150 \times 0,1^{0,63 \times} 0,00609 \\
& 0,54=0,793 \mathrm{~m} / \mathrm{dtk}
\end{aligned}
$$

Pipa Distribusi yang Direncanakan

\section{Untuk Blok II}

Debit (q) $=72,926$ liter $/ \mathrm{dtk}$

Panjang pipa

$$
=432 \mathrm{~m}
$$

D

$=75 \mathrm{~mm}$

$\mathrm{C}_{\mathrm{HW}}$

$$
=150
$$

- Kehilangan dalam pengaliran

$H f=\frac{10,675 x Q^{1,852}}{C H W^{1,852} \times D^{4,8704}} x L$

$H f=\frac{10,675 \times 0,07926^{1,852}}{150^{1,852} \times 0,10,075^{4,8704}} \times 432=3,665 \mathrm{~m}$

- Kontrol

$\mathrm{Hf}<\Delta \mathrm{H}$ (Elevasi pipa reservoir - Elevasi di Zona 1)
$3,665 \mathrm{~m}<14 \mathrm{~m}$ . $\mathrm{ok}$

- Menghitung Kecepatan Aliran

$\mathrm{v} \quad=0,3545 \mathrm{C}_{\mathrm{HW}} \mathrm{D}^{0,63} \mathrm{~S}^{0,54}$

$\mathrm{S} \quad=\mathrm{Hf} / \mathrm{L}=3,655 / 432=0,00845$

$\mathrm{v} \quad=0,3545 \times 150 \times 0,075^{0,63} \times$

$0,00845^{0,54}$

$=0,759 \mathrm{~m} / \mathrm{dtk}$

\section{Pipa Distribusi Dari Reservoar Distribusi ke Pelanggan}

Reservoar dibuat karena aliran air yang terjadi tidaklah statis. Pada jam tertentu aliran air yang dibutuhkan lebih kecil dari debit rata-rata akan tetapi kadang pada jam sibuk aliran air yang dibutuhkan lebih besar dari debit kebutuhan rata rata. Oleh karena itu dibutuhkan reservoar distribusi agar menanggulangi aliran air yang tidak statis ini.

Perhitungan Kapasitas Reservoar Distribusi

Debit yang direncanakan untuk mendesain kapasitas reservoar distribusi berdasarkan besarnya kebutuhan total pada tahun 2028 yaitu 72,926 liter/detik = $656,334 \mathrm{~m}^{3} /$ hari. Direncanakan Suplai air pemompaan merata dalam 8 jam mulai dari jam 06.00 - 07.00 sampai jam 13.00 - 14.00 dimana total suplai air dalam 8 jam sama dengan besarnya kebutuhan total seperti yang ditunjukkan pada tabel di bawah ini. 
Tabel 6 Perhitungan Air di reservoar

\begin{tabular}{|l|l|l|l|}
\hline Jam & \multicolumn{1}{|c|}{$\begin{array}{c}\text { Suplai Air Penampungan } \\
\left(\mathbf{m}^{\mathbf{3}}\right)\end{array}$} & $\begin{array}{c}\text { Pemakaian Air di Perum } \\
\text { Green Kemiling } \\
\left(\mathbf{m}^{\mathbf{3}}\right)\end{array}$ & $\begin{array}{c}\text { Volume Air di } \\
\text { Reservoar } \\
\left(\mathbf{m}^{\mathbf{3}}\right)\end{array}$ \\
\hline $00-01$ & 0,00 & 0,00 & $\mathrm{X}$ \\
\hline $01-02$ & 0,00 & 0,00 & $\mathrm{X}$ \\
\hline $02-03$ & 0,00 & 0,00 & $\mathrm{X}$ \\
\hline $03-04$ & 0,00 & 0,00 & $\mathrm{X}$ \\
\hline $04-05$ & 0,00 & 0,00 & $\mathrm{X}$ \\
\hline $05-06$ & 0,00 & 14,97 & $\mathrm{X}-14,97$ \\
\hline $06-07$ & 67,33 & 57,30 & $\mathrm{X}-4,94$ \\
\hline $07-08$ & 67,33 & 63,01 & $\mathrm{X}-0,62$ \\
\hline $08-09$ & 67,33 & 48,95 & $\mathrm{X}+17,75$ \\
\hline $09-10$ & 67,33 & 33,77 & $\mathrm{X}+51.31$ \\
\hline $10-11$ & 67,33 & 16,56 & $\mathrm{X}+102,8$ \\
\hline $11-12$ & 67,33 & 15,57 & $\mathrm{X}+153,84$ \\
\hline $12-13$ & 67,33 & 21,28 & $\mathrm{X}+199,89$ \\
\hline $13-14$ & 67,33 & 13,04 & $\mathrm{X}+254,18$ \\
\hline $14-15$ & 0,00 & 11,06 & $\mathrm{X}+243,12$ \\
\hline $15-16$ & 0,00 & 29,19 & $\mathrm{X}+213,92$ \\
\hline $16-17$ & 0,00 & 67,94 & $\mathrm{X}+150,99$ \\
\hline $17-18$ & 0,00 & 58,52 & $\mathrm{X}+92,47$ \\
\hline $18-19$ & 0,00 & 46,33 & $\mathrm{X}+46,14$ \\
\hline $19-20$ & 0,00 & 21,97 & $\mathrm{X}+24,17$ \\
\hline $20-21$ & 0,00 & 18,34 & $\mathrm{X}+5,83$ \\
\hline $21-22$ & 0,00 & 5,83 & $\mathrm{X}$ \\
\hline $22-23$ & 0,00 & 0,00 & $\mathrm{X}$ \\
\hline $23-24$ & 0,00 & 0,00 & $\mathrm{X}$ \\
\hline Total & 656,334 & 656,334 & \\
\hline & & \\
\hline
\end{tabular}

Volume minimal $\mathrm{X}=\mathrm{X}-14,97$

Pada volume minimal bak tepat kosong $=\mathrm{X}-14,97=0$

Volume maksimum $=14,97+254,18=$ 269,15

Maka kapasitas tampung dari reservoar $=$ $269,15 \mathrm{~m}^{3}$

Menentukan ukuran reservoar :

Volume reservoar $>269,15 \mathrm{~m}^{3}$

$\mathrm{px} 1 \times \mathrm{t} \quad>269,15 \mathrm{~m}^{3}$

Direncanakan :

Panjang : $: 12 \mathrm{~m}$

Lebar : $12 \mathrm{~m}$

Tinggi : $2 \mathrm{~m}$
Dalam hal ini tinggi merupakan kedalaman dari kapasitas air, sehingga dimensi yang direncanakan harus lebih besar dari jumlah pemakaian air yang ada.

$$
\begin{array}{lll}
12 \mathrm{~m} \times 12 \mathrm{~m} \times 2 \mathrm{~m} & > & 269,15 \mathrm{~m}^{3} \\
288 \mathrm{~m}^{3} & > & 269,15 \mathrm{~m}^{3}
\end{array}
$$

Direncanakan tinggi jagaan $0,5 \mathrm{~m}$ dan tinggi kapasitas mati adalah 0,2 m. Sehingga total tinggi dari reservoar adalah $2 \mathrm{~m}+0,5 \mathrm{~m}+0,2 \mathrm{~m}=2,7 \mathrm{~m}$ Maka dimensi reservoar distribusi adalah $=12 \mathrm{~m} \times 12 \mathrm{~m} \mathrm{x} 2,7 \mathrm{~m}$. 


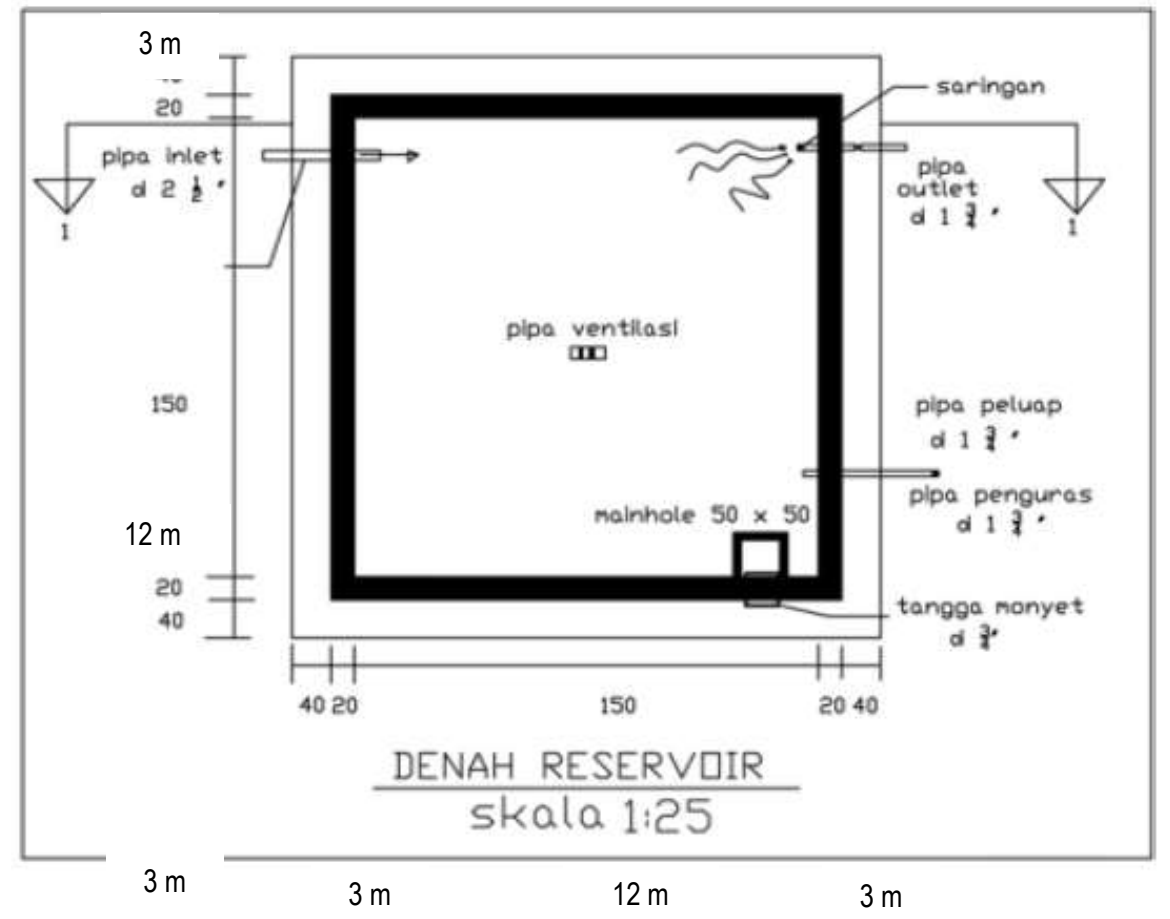

Gambar 6 Denah Rencana Reservoar

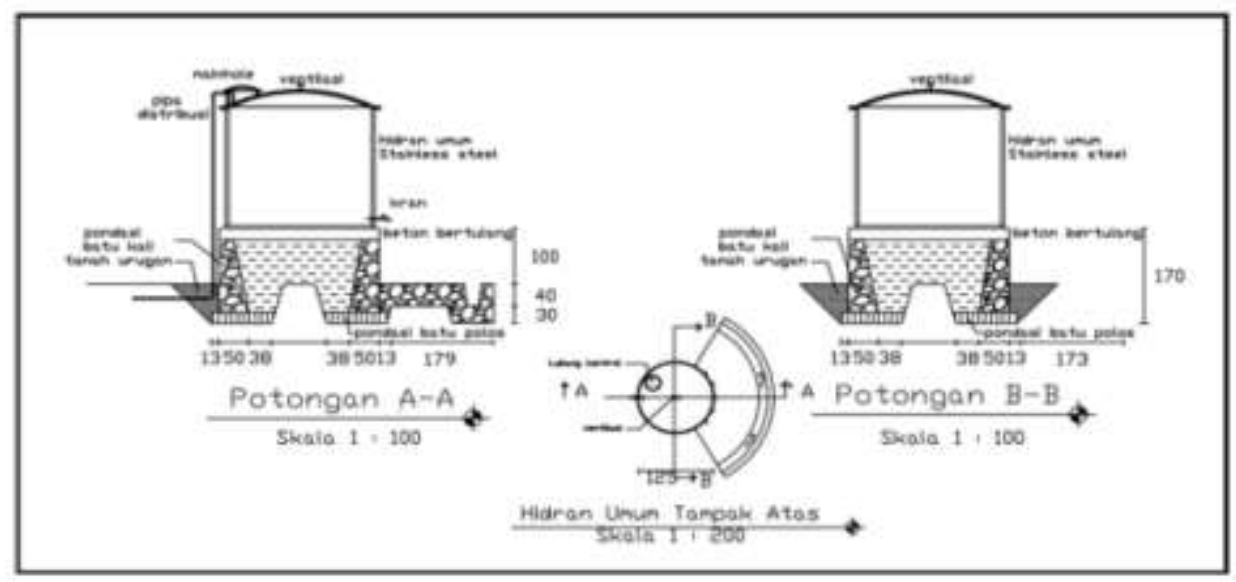

Gambar 7 Denah Rencana Reservoar

\section{Kesimpulan Dan Saran}

Dari hasil kajian dan analisis data, diperoleh kesimpulan sebagai berikut:

1. Kebutuhan air bersih dengan pelayanan $80 \%$ di zona pelayanan Perumahan Green Kemiling sampai dengan 2028 mencapai 72,926 liter/dtk.
2. Pengembangan sistem penyediaan air bersih terdiri dari pompa transmisi pompa dilakukan dengan pipa 200 mm dengan elevasi +28 menghasilkan kehilangan sebesar 5,646 m atau lebih rendah dari selisih elevasi pipa sumur dalam sebesar 7 m. 
3. Jaringan transmisi air bersih dan pompa dari bak penampungan menuju reservoir distribusi menggunakan pipa HDPE 100mm dengan elevasi dasar bak penampung $+25,75 \mathrm{~m}$ dengan kehilangan $\mathrm{hf}=0,035 \mathrm{~m}$

4. Pembagian sistem air bersih dibagi menjadi 2 blok zona dengan kehilangan sebesar 0,280 m untuk blok I dan 3,665 m untuk blok II.

\section{Daftar Pustaka}

Direktorat Jenderal Cipta Karya, 2007. Rencana Program Investasi Jangka Menengah Bidang PU/ Cipta Karya, Jakarta.

Sarwoko, 2004. Penyediaan Air Bersih untuk Kawasan Permukiman, Lembaga Penelitian UNS, Semarang

Sudjawadi, 1987. Dasar - dasar teknik irigasi, KMTS - UGM, Yogyakarta.

Supranto, 1984. Ekonometrik (Buku Satu dan Buku dua). Lembaga Penerbit Fakultas Ekonomi UI, Jakarta.

Sutrisno, Totok.C. Suciastuti, Eny, 1987, Teknologi Penyediaan Air Bersih, Bina Aksara, Jakarta.

Triatmadjo, Radianta, 2008, Sistem Penyediaan Air Minum Perpipaan, Yogyakarta.

Triadmodjo, B., 1996, Hidrolika II, Beta Offset, Yogyakarta.

Peraturan Pemerintah No. 16 Tahun 2005 tentang Sistem Penyediaan Air Minum (SPAM)

Undang - Undang No. 7 Tahun 2004 tentang Sumber Daya Air. 